\title{
Biocompatibility, Bioactivity and Mechanical Properties of Portland Cement and Portland Cement-Metakaolin Blends for Bone Tissue Engineering Applications
}

\author{
Daniel Gallego ${ }^{1}$, Natalia Higuita ${ }^{1}$, Felipe Garcia ${ }^{2}$, Olga M. Posada ${ }^{2}$, Luis E. Lopez ${ }^{2}$, Alan S. \\ Litsky $^{1}$, and Derek J. Hansford ${ }^{1}$ \\ ${ }^{1}$ Biomedical Enginering Department, The Ohio State University, 1080 Carmack Road (Bevis \\ Hall, Suite 270), Columbus, OH, 43210 \\ ${ }^{2}$ Grupo de Investigacion en Ingenieria Biomedica EIA-CES (GIBEC), Envigado, Colombia
}

\begin{abstract}
We studied the potential applications of Portland cement and Portland cementMetakaolin blends as scaffolding materials for load bearing bone tissue engineering. Cementitious pastes were prepared by mixing Portland cement and Metakaolin at different ratios (100:0, 85:15), and hydrated under a concentrated $\mathrm{CO}_{2}$ atmosphere (carbonated pastes). Pastes fabricated similarly, but hydrated under normal atmospheric conditions were used for comparison (non-carbonated pastes). Compressive tests were run to evaluate the mechanical properties of the pastes. The bioactivity of the samples was tested in a simulated body fluid (SBF) solution for 1 and 4 days. Sample morphology and chemistry were characterized via scanning electron microscopy (SEM) and energy dispersive spectroscopy (EDS), respectively. The cytocompatibility was studied using human osteosarcoma (HOS) cell cultures and the direct contact assay. Mechanical characterization did not show significant differences in the compressive strength of the blends compared to pure cement controls. The bioactivity test revealed that the pastes induced surface precipitation of calcium phosphate $(\mathrm{CaP})$ when exposed to the SBF solution (as confirmed by SEM and EDS). Non-carbonated pastes induced early $\mathrm{CaP}$ precipitation. Cytocompatibility experiments showed that the carbonated blends allowed adequate cell growth. Non-carbonated blends presented a highly cytotoxic behavior. The introduction of Metakaolin did not affect the cytocompatibility of the samples. These results show that Portland cement and Portland cement-Metakaolin blends could present suitable characteristics for applications as scaffolding materials in load bearing bone tissue engineering.
\end{abstract}

\section{INTRODUCTION}

Bone substitutes are required to repair osseous defects caused by a number of factors, such as traumas, degenerative diseases, cancer, and others. Bone autografts and allografts have traditionally been used to treat these problems; however, their implementation still presents several disadvantages, including the lack of donors, potential of immune rejection, possible pathogen transmission, and high donor site morbidity among others [1].

Bone tissue engineering (BTE) aims to restore lost or damaged bone tissue by combining cells, scaffolds and growth factors and thereby overcome the drawbacks presented by conventional auto and allografting procedures [2]. Previous research in the development of scaffolding materials for BTE has allowed us to identify a set of minimum required characteristics to achieve satisfactory bone tissue repair. Such materials are expected to exhibit high biocompatibility, bioactivity, and adequate mechanical strength for this application [1-4]. 
A number of biomaterials, including metals, ceramics, polymers, and composites have been studied for the production of scaffolds in BTE applications. However, the majority of materials developed until now present several disadvantages. Metals exhibit susceptibility to corrosion, poor osseointegration, and stress shielding $[2,5]$. Ceramics tend to be brittle, present low mechanical strength (in a porous configuration), and unpredictable in vivo degradation/dissolution rates $[1,2,6,7]$. Polymers on the other hand show reduced osseointegration capabilities, decreased cell-material interactions due to surface hydrophobicity, and excessive ductility for hard tissue replacement applications [1, 2, 8]. Recent research has been highly focused on the development of polymer-ceramic nanocomposites [1]. Such composites tend to present superior strength compared to the individual constituent materials. Nevertheless, the increase in strength still seems to be "below expectations", probably due to low polymer/ceramic interfacial strength [9]. Achieving high strength at the interface still remains a major challenge [1].

As shown above, the field of BTE is still in need of a scaffolding material capable of providing suitable structural and biological characteristics for bone repair. In this paper we studied the properties of two widely available, inexpensive, and yet technologically advanced materials (i.e. Portland cement and Metakaolin), for BTE applications. Portland cement is one of the most extensively used construction materials in the world [10]. This cement is mainly composed of calcium silicates (tricalcium silicate $\left(\mathrm{C}_{3} \mathrm{~S}\right)$, and dicalcium silicate $\left(\mathrm{C}_{2} \mathrm{~S}\right)$ ). Metakaolin is a pozzolan primarily composed of silica $\left(\mathrm{SiO}_{2}\right)$ and alumina $\left(\mathrm{Al}_{2} \mathrm{O}_{3}\right)$ [11]. This material has been widely used as a supplement for mortar and concrete production. Portland cement-based materials (i.e. mineral trioxide aggregate (MTA)) have been successfully used in endodontic applications [12]. MTA has been known to stimulate dentinogenesis and cementogenesis [13]. However, the implementation of Portland cement as scaffolding material for BTE applications has not yet been fully explored.

\section{EXPERIMENTAL DETAILS}

Portland cement and Portland cement-Metakaolin blends were prepared by mixing White Type I Portland cement (Cementos Argos, Colombia) with Metakaolin (PowerPozz, USA) at 2 different ratios (100:0, and 85:15 wt/wt). The slurry was mixed with distilled water at a 2:1 ratio, molded into cylindrical specimens, and hydrated under a $20 \% \mathrm{CO}_{2}$ atmosphere, $\sim 90 \%$ relative humidity, at $37^{\circ} \mathrm{C}$ for 8 days. Hydrated Portland cement possesses a highly basic $\mathrm{pH}$ [10] which could cause detrimental effects to living tissues. The $\mathrm{CO}_{2}$ treatment was implemented to try to reduce the basicity of this material [14]. Specimens fabricated similarly, but hydrated under normal atmospheric conditions were used for comparison (non-carbonated samples). The mechanical properties of the specimens $(2 \mathrm{~cm}$ diameter $\times 2.5 \mathrm{~cm}$ height) were evaluated via compressive tests.

A bioactivity test was conducted by immersing the samples (cross-sectioned $2 \mathrm{~cm}$ diameter $x 0.5 \mathrm{~cm}$ height cylinders) in a SBF solution, with similar ion concentrations to human blood plasma, at $36.5^{\circ} \mathrm{C}$ for 1 and 4 days, according to a procedure formerly described by Kokubo and Takadama (2006) [4]. Calcium phosphate (CaP) precipitation (indicator of bioactivity) was examined via SEM/EDS (S-3000H). For this, the samples were previously coated with a thin $(\sim 10 \mathrm{~nm}) \mathrm{Au} / \mathrm{Pd}$ layer.

The cytocompatibility of the samples ( $2 \mathrm{~cm}$ diameter $\mathrm{x} 0.5 \mathrm{~cm}$ height) was tested using a direct contact assay (DCA) [15]. Briefly, human osteosarcoma (HOS) cells (ATCC, USA) were 
seeded in six well plates at a density of $\sim 3 \times 10^{4}$ cells $/ \mathrm{cm}^{2}$, and incubated in minimum essential medium (Sigma, USA), supplemented with $10 \%$ fetal bovine serum (GIBCO, USA) and 1\% antibiotics/antimycotics (GIBCO, USA) at $37^{\circ} \mathrm{C}$ and $5 \% \mathrm{CO}_{2}$ for 48 hours. Previously sterilized (by autoclaving) cementitious samples (both carbonated and non-carbonated) were then placed on top of each cell monolayer, and the cultures were incubated for another 24 hours under the same conditions. After that, the samples were removed, and cell viability was evaluated using the trypan blue dye exclusion method. Cell culture medium was used as negative non-cytotoxic control.

Numerical data (elastic modulus, compressive strength, and cell viability) was statistically analyzed using a one-way ANOVA and a student t test at a 95\% level of confidence. A total of 20 samples were used in the mechanical characterization (10 for each group). Cell cultures were run in triplicate.

\section{RESULTS AND DISCUSSION}

SEM characterization showed that the microscale surface morphology was relatively consistent for all samples. The presence of Metakaolin was confirmed by increased Si and $\mathrm{Al}$ peaks in the EDS spectra (data not shown). Carbonated specimens showed presence of calcium carbonate $\left(\mathrm{CaCO}_{3}\right)$ crystals (Figure $\left.1 \mathrm{~A}, \mathrm{~B}\right)$. During hydration, the calcium silicates in Portland cement react with water to produce calcium silicate hydrate $(\mathrm{C}-\mathrm{S}-\mathrm{H})$ and calcium hydroxide $\left(\mathrm{Ca}(\mathrm{OH})_{2}\right)$. These two compounds provide strength and high alkalinity to the paste, respectively [10]. The introduction of $\mathrm{CO}_{2}$ caused formation of $\mathrm{CaCO}_{3}$ due to carbonation of the $\mathrm{Ca}(\mathrm{OH})_{2}$ [14]. As expected, carbonated samples showed increased carbon peaks in the EDS spectra (Figure $1 \mathrm{C}$ ).
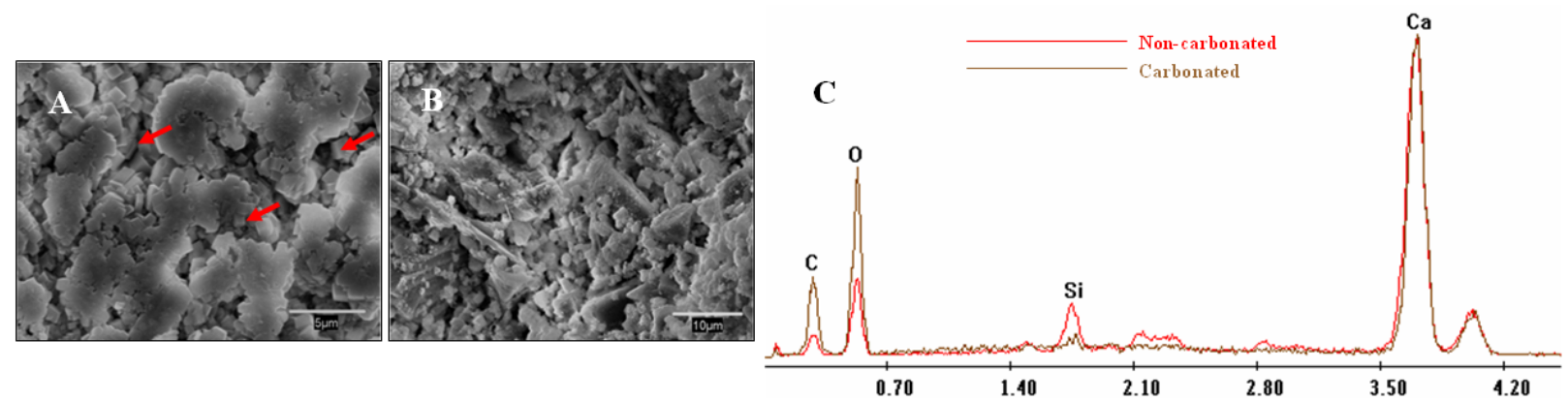

Figure 1. A. Carbonated cement sample ( $0 \%$ Metakaolin) showing presence of $\mathrm{CaCO}_{3}$ crystals on the surface (red arrows). B. Non carbonated cement sample (0\% Metakaolin). C. EDS spectra comparing carbonated and non-carbonated samples.

When combined with Portland cement, the active $\mathrm{SiO}_{2}$ in Metakaolin reacts with the $\mathrm{Ca}(\mathrm{OH})_{2}$ liberated during hydration, thus causing additional formation of $\mathrm{C}-\mathrm{S}-\mathrm{H}$ (pozzolanic reaction) [11]. This is typically reflected in a long-term (after $\sim 30$ day hydration period) increase in the strength of the paste. In our case (8 days of hydration), the mechanical characterization did not reveal significant differences $(p>0.05)$ in compressive strength and elastic modulus when comparing specimens with and without metakaolin (Table I). However, long-term evaluation ( $\sim 30$ days of hydration) is expected to yield pastes with superior mechanical performance, as the pozzolanic reaction will be completed, and there will be additional $\mathrm{C}-\mathrm{S}-\mathrm{H}$ to contribute to the strength of the sample. 
Table I. Compressive strength and elastic modulus of carbonated pastes

\begin{tabular}{|c|c|c|}
\hline Type & Compressive strength (MPa) & Elastic modulus (MPa) \\
\hline Portland cement & $21.27 \pm 4.92$ & $1273.52 \pm 533.28$ \\
\hline $\begin{array}{c}\text { Portland cement + 15\% } \\
\text { Metakaolin }\end{array}$ & $19.90 \pm 5.20$ & $1103.73 \pm 360.71$ \\
\hline
\end{tabular}

SEM and EDS characterization revealed that the cementitious specimens (carbonated and non-carbonated, with and without Metakaolin) presented surface precipitation of $\mathrm{CaP}$ after exposure to the SBF solution. This was confirmed by the presence of phosphorous peaks in the EDS spectra. Non-carbonated specimens (with and without Metakaolin) exhibited calcium phosphate precipitation after day 1 (Figure 2 A-C). Carbonated samples without Metakaolin showed CaP precipitation only after day 4 (Figure $2 \mathrm{D}-\mathrm{F}$ ). However, carbonated samples with Metakaolin presented $\mathrm{CaP}$ precipitation at day 1 . The $\mathrm{pH}$ of the samples influenced the chemistry of the precipitates. Non-carbonated samples ( 0 and $15 \%$ Metakaolin) showed high content of $\mathrm{Mg}$ on the surface. Non-carbonated samples without Metakaolin exhibited Mg traces after day 4.

Early $\mathrm{CaP}$ precipitation on non-carbonated samples could probably be attributed to the higher $\mathrm{pH}$ of these specimens $[4,13]$. In previous research, we were able to induce surface precipitation of apatite-like crystals on carbonated cement substrates via exposure to a concentrated calcium phosphate solution to potentially enhance the bioactivity of the material [16]. The results presented in this work showed, however, that carbonated Portland cement is capable of inducing $\mathrm{CaP}$ precipitation when exposed to physiologic-like solutions (indicator of bioactivity).

Nevertheless, pre-precipitation of apatite-like crystals may help to induce earlier CaP deposition on carbonated samples when subjected to physiologic fluids.
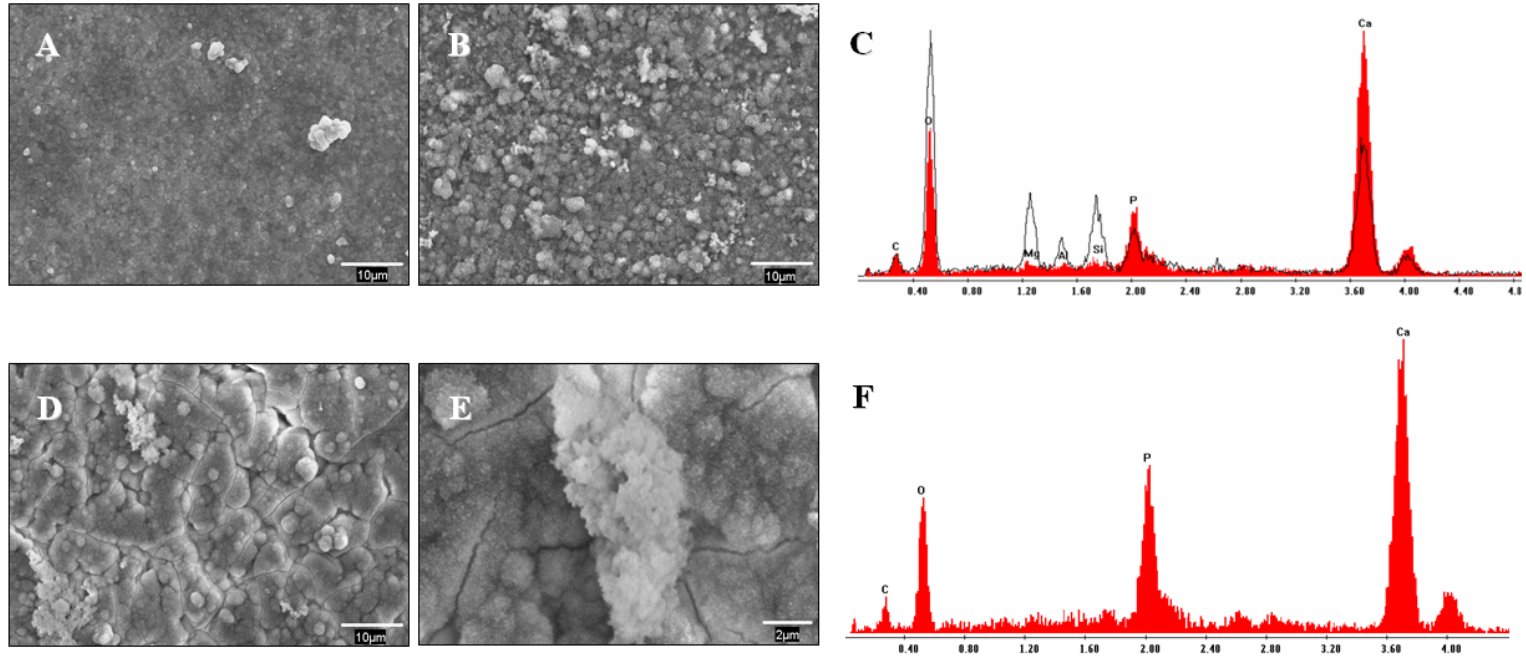

Figure 2. $\mathrm{CaP}$ precipitates (after 1 day of exposure to the $\mathrm{SBF}$ solution) on non-carbonated specimens without (A) and with (B) $15 \%$ of Metakaolin. C. EDS spectra comparing A (red) and B (black). CaP precipitates (after 4 days of exposure to the SBF solution) on carbonated specimens ( $0 \%$ Metakaolin) (D, E). F. EDS spectra of $\mathbf{E}$.

The cytocompatibility experiments showed that non-carbonated pastes exhibited an extremely cytotoxic behavior. The vast majority of cells that were in direct contact with noncarbonated samples (and $\sim 1 \mathrm{~mm}$ beyond) died (Figure $3 \mathrm{~A}$ ). On the other hand, cells cultured in the presence of carbonated specimens were not significantly affected by the cementitious paste 
(Figure 3 B). Cell viability was considerably higher $(p=0.0006)$ in cultures that were incubated with carbonated samples (Figure $3 \mathrm{C}$ ). No significant differences in viability were found between carbonated samples and the negative control (culture medium). The DCA showed that the introduction of Metakaolin did not have any significant effect on the cytocompatibility of the samples. The cytotoxic behavior of non-carbonated specimens could be attributed to the high alkalinity of these samples $(\mathrm{pH} \sim 13)$. The $(\mathrm{OH})^{-}$ions released after dissociation of the $\mathrm{Ca}(\mathrm{OH})_{2}$ in aqueous media are known to cause cell death [17]. Carbonated specimens presented a more neutral $\mathrm{pH}$ (due to a reduction in the $\mathrm{Ca}(\mathrm{OH})_{2}$ levels by carbonation and/or the pozzolanic reaction) thus providing a more compatible environment for cell growth. The implementation of larger amounts of Metakaolin ( 20-25\% by weight) and longer hydration periods could potentially cause a significant decrease in the cytotoxicity of non-carbonated pastes, as the levels of $\mathrm{Ca}(\mathrm{OH})_{2}$ could be reduced considerably due to completion of the pozzolanic reaction [11].
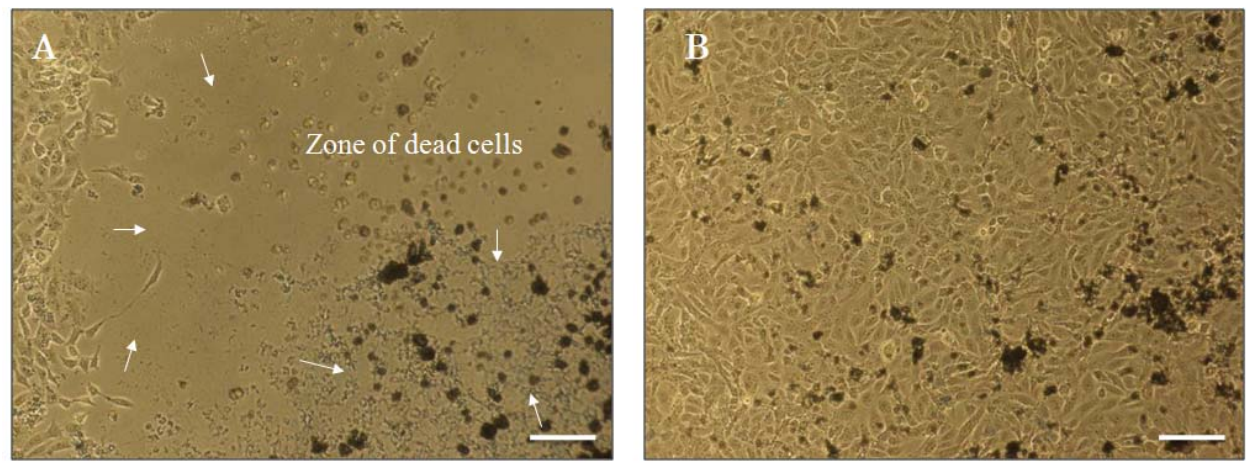

C

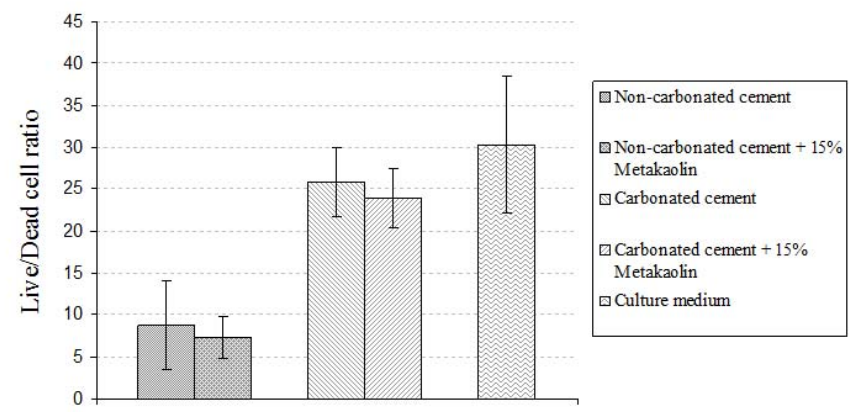

Figure 3. A. HOS cells cultured in the presence of a non-carbonated cement sample. White arrows show a zone of dead cells (equivalent to the area covered by the sample, and $\sim 1 \mathrm{~mm}$ beyond). B. HOS cells cultured in the presence of a carbonated cement sample. C. Cell viability graph (cell viability was determined by analyzing all the remanent cells in each well). Dark bodies (possibly debris from the cement and dead cells) were observed. The scale bar in A. and B. equals $100 \mu \mathrm{m}$.

\section{CONCLUSIONS}

Portland cement and Portland cement-metakaolin blends with suitable properties for load bearing bone tissue engineering applications were prepared. The cementitious samples presented high mechanical strength. Non-carbonated specimens showed increased bioactivity and a cytotoxic effect on pre-cultured cell monolayers. Carbonated samples exhibited reduced bioactivity in comparison to non-carbonated samples; however, these specimens presented a highly cytocompatible behavior (comparable to culture medium). These results show the 
possibility of obtaining scaffolding materials suitable for bone repair applications from widely available, low priced, and technologically advanced materials.

\section{ACKNOWLEDGMENTS}

The authors would like to thank professor Jonas Klemas (posthumous), AFOSR MURI, COLCIENCIAS, and the staff of the Nanotech West Laboratory for technical assistance.

\section{REFERENCES}

1. Ministry, A.S., Mikos, A.G., Tissue engineering strategies for bone regeneration. Adv. Biochem Engin/Biotechnol, 2005. 94: p. 1

2. Salgado, A.J., Coutinho, O.P., Reis, R.L., Bone Tissue Engineering: State of the Art and Future Trends. Macromolecular Bioscience, 2004. 4: p. 776

3. Temenoff, J.S., Mikos, A.G., Review: tissue engineering for regeneration of articular cartilage. Biomaterials, 2000. 21: p. 2405

4. Kokubo, T., Takadama, H., How useful is SBF in predicting in vivo bone bioactivity?. Biomaterials, 2006. 27: p. 2907

5. Kokubo, T., Kim, H.M., Kawashita, M., Novel bioactive materials with different mechanical properties. Biomaterials, 2003. 24: p. 2161

6. Friedman, C.D., Costantino, P.D., Takagi, S., Chow, L.C., Bone source ${ }^{\mathrm{TM}}$ hydroxyapatite cement: a novel biomaterial for craniofacial skeletal tissue engineering and reconstruction. J Biomed Mater Res (Appl Biomater), 1998. 43: p. 428

7. Adams, C.S., Mansfield, K., Perlot, R.L., Shapiro, I.M., Matrix Regulation of Skeletal Cell Apoptosis. J. Biol. Chem., 2001. 276: p. 20316

8. Kim, H.M., Kishimoto, K., Miyaji, F., Kokubo, T., Yao, T., Suetsugu, Y., Tanaka, J., Nakamura, T., Composition and structure of the apatite formed on PET substrates in SBF modified with various ionic activity products. J Biomed Mater Res, 1999. 46: p. 228

9. Rezwan, K., Chen, Q.Z., Blaker, J.J., Boccaccini, A.R., Biodegradable and bioactive polymer/inorganic composite scaffolds for bone tissue engineering. Biomaterials, 2006. 27: p.3413

10. Aitcin, P.C., Cements of yesterday and today Concrete of tomorrow. Cement and Concrete Research, 2000. 30: 1349

11. Sabir, B.B., Wild S., Bai, J., Metakaolin and calcined clays as pozzolans for concrete: a review. Cement \& Concrete Composites, 2001. 23: p. 441

12. Sarkar, N.K., Caicedo, R., Ritwik, P., Moiseyeva, R., Kawashima, I., Physicochemical basis of the biological properties of mineral trioxide aggregate. J Endod, 2005. 31: p.97

13. Tay, F.R., Pashley, D.H., Guided tissue remineralization of partially demineralized human dentine. Biomaterials, 2007. 29: p.1127

14. Cultrone, G., Sebastian, E., Ortega Huertas, M., Forced and natural carboation of lime-based mortars with and without additives: mineralogical and textural changes. Cement and Concrete Research, 2005. 35: p. 2278

15. Northup SJ, Cammack JN. Mammalian cell culture models. En: Handbook of biomaterial evaluation: scientific, technical, and clinical testing of implant materials. 2 ed, Ann Arbor, Taylor \& Francis, 1999, 329

16. Gallego, D., Higuita, N., Garcia, F., Ferrell, N., Hansford, D.J., Bioactive coatings on Portland cement substrates: Surface precipitation of apatite-like crystals. Materials Science and Engineering C, 2008. 28: p. 347

17. Huang, F.M., Tai, K.W., Chou, M.Y., Chang, Y.C., Cytotoxicity of resin-, zinc oxide-eugenol-, and calcium hydroxide-based root canal sealers on human periodontal ligament cells and permanent V79 cells. International Endodontic Journal, 2002. 35: p. 153 